Review

\title{
Teaching individuals with autism spectrum disorder to ask questions: A systematic review
}

\author{
Tracy Raulston a ${ }^{\mathrm{a}}$, Amarie Carnett ${ }^{\mathrm{a}}$, Russell Lang a,b,*, Amy Tostanoski ${ }^{\mathrm{a}}$, \\ Allyson Lee ${ }^{\mathrm{a}}$, Wendy Machalicek ${ }^{\mathrm{c}}$, Jeff Sigafoos ${ }^{\mathrm{d}}$, Mark F. O'Reilly ${ }^{\mathrm{b}}$, \\ Robert Didden ${ }^{\mathrm{e}}$, Giulio E. Lancioni ${ }^{\mathrm{f}}$ \\ ${ }^{a}$ Clinic for Autism Research Evaluation and Support at Texas State University-San Marcos, United States \\ ${ }^{\mathrm{b}}$ Meadows Center for the Prevention of Educational Risk at The University of Texas at Austin, United States \\ ${ }^{\mathrm{c}}$ University of Oregon, United States \\ d Victoria University of Wellington, New Zealand \\ ${ }^{\text {e }}$ Radboud University Nijmegen, The Netherlands \\ ${ }^{\mathrm{f}}$ University of Bari, Italy
}

\section{A R T I C L E I N F O}

\section{Article history:}

Received 22 March 2013

Accepted 26 March 2013

\section{Keywords:}

Autism

Question

Communication

Review

Behavioral intervention

\begin{abstract}
A B S T R A C T
This review involved a systematic search and analysis of studies aimed at teaching individuals with autism spectrum disorder (ASD) to ask questions (i.e., teaching mands for information). A systematic search of databases, reference lists, and journals identified 21 studies that met predetermined inclusion criteria. Included studies were then summarized in terms of (a) participant characteristics, (b) dependent variables (e.g., types of question-asking skills that were taught), (c) intervention procedures, (d) research designs, and (e) outcomes. All 21 studies reported that participants acquired or improved in the targeted question-asking skills. The most common intervention components included (a) echoic prompts and systematic fading procedures (e.g., time delay), (b) positive reinforcement via provision of requested information and/or access to preferred items or activities, and (c) contriving situations to motivate specific questions (i.e., creating establishing operations). Implications for practitioners and directions for future research are discussed.
\end{abstract}

\section{Contents}

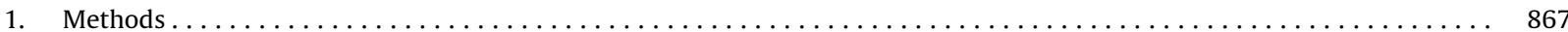

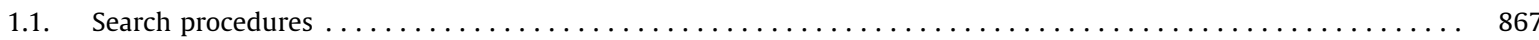

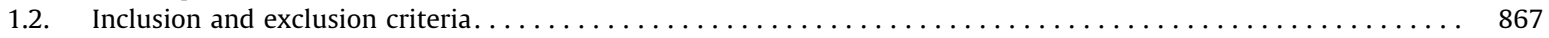

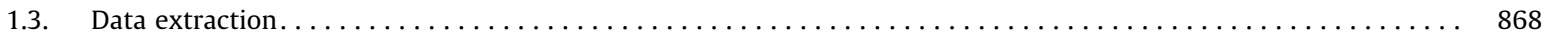

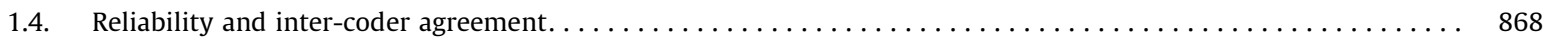

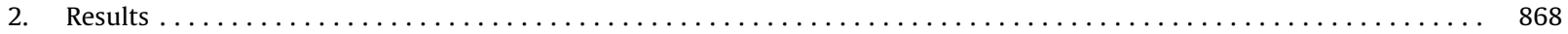

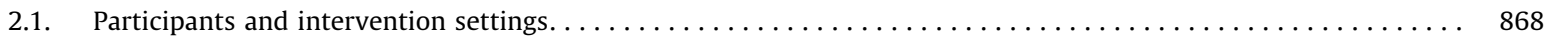

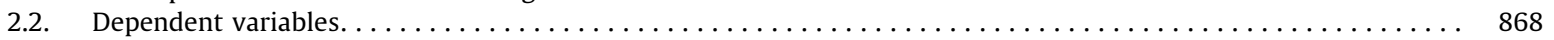

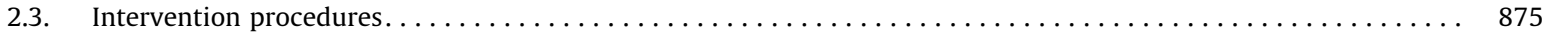

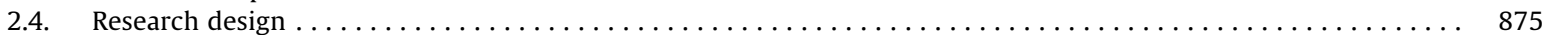

\footnotetext{
* Corresponding author at: 601 University Drive, San Marcos, TX 78666, United States.

E-mail address: russlang@txstate.edu (R. Lang).
} 
Typically developing children experience a rapid increase in spoken language between two and three years of age. This is sometimes referred to as a "language explosion" (Brown, 1968; Brown, Cazden, \& Bellugi-Klima, 1969; Panico, Daniels, \& Claflin, 2011). During this developmental period, specific forms of questions (e.g., what?, where?, and how?) often emerge in a predictable developmental sequence (Bloom, Merkin, \& Wooten, 1982; Smith, 1933; Tyack \& Ingram, 1977). From a behavioral perspective, questions are defined by their functional properties and question-asking is classified as a type of request (or mand) for information (Skinner, 1957). For example, "Please tell me the time." and "What time is it?" are both mands for information that are typically reinforced in the natural environment by the provision of the requested information from a communication partner (e.g., "It is 8:48.").

Learning to ask questions (i.e., to mand for information) is paramount for academic success, social interaction, adaptive functioning (e.g., locating a restroom in an unfamiliar environment), and many forms of employment (Brown, 1968; Brown et al., 1969; Chouinard, 2007; Fahey, 1942; Koegel, Carter, \& Koegel, 2003; Lewis, 1938; Light \& Binger, 1998; Ostryn \& Wolfe, 2011a; Secan, Egel, \& Tilley, 1989; Skinner, 1957; Smith, 1933; Sundberg \& Michael, 2001; Sundberg \& Partington, 1998; Tyack \& Ingram, 1977). Koegel et al. (2003) pointed out that teaching question-asking might also allow students to access more learning opportunities in less restrictive settings. Unfortunately, many individuals with autism spectrum disorders (ASD) do not seem to readily learn to ask questions, ask too few questions, or ask unusual or inappropriate questions (e.g., Stone, Ousley, Yoder, Hogan, \& Hepburn, 1997; Wetherby \& Prutting, 1984). Such deficits in question-asking can inhibit academic achievement and social interaction, and more generally reduce the person's overall quality of life.

Given the importance of question-asking skills and the deficits in question-asking that are experienced by some individuals with ASD, it is not surprising that intervention research has focused on improving this aspect of communication. Although many reviews involving communication intervention for individuals with ASD have been recently published (e.g., Duffy \& Healy, 2011; Ganz, Earles-Vollrath, et al., 2012; Ramdoss et al., 2011), a review specific to teaching question-asking skills is warranted because of the aforementioned importance of question-asking skills. In this systematic review, we provide an overview of studies in which participants with ASD received intervention specifically designed to improve questionasking skills. Each included study is summarized in terms of participant characteristics, types of question-asking skills taught, the intervention components that were implemented, the study's research design, and the outcomes for participants. A review of this nature is intended to elucidate potential directions for future research and to help practitioners identify evidence-based interventions.

\section{Methods}

This review consisted of a systematic search and analysis of studies that provided intervention to teach individuals with ASD to ask questions or improve existing question-asking skills. First, a systematic search procedure was implemented. Next, predetermined inclusion criteria were applied to studies returned by the search. Included studies were then summarized by two or more co-authors independently and these summaries were then checked for accuracy across co-authors.

\subsection{Search procedures}

Systematic searches were conducted in four electronic databases: Education Resources Information Center (ERIC), Psychology and Behavioral Sciences Collection, Medline, and PsycINFO. The search was limited to peer-reviewed studies written in English. To focus the search on studies most likely to meet the inclusion criteria, three lists of key terms were created. List 1 included terms or phrases related to question-asking skills (i.e., "question*," "mand* for information," "request* information," and "Wh question"). List 2 included terms related to intervention (i.e., "intervention," "teach"," "therap"," and "treatment"). List 3 involved terms related to ASD diagnosis (i.e., "auti"," "PDD-NOS," and "Asperger"”). Each search included one term from each list (e.g., "question"”, and "intervention", and "autis*") that was inserted as free text into the keyword fields. All possible combinations of terms across lists were searched separately. Two co-authors independently screened the returned abstracts from the search to identify studies for possible inclusion in this review. The reference lists of the studies identified for possible inclusion by each co-author were then reviewed to identify additional studies for possible inclusion. Finally, to identify studies that had not yet been uploaded to the electronic databases, hand searches that covered the period January 2011 to January 2012 were conducted for each journal that had published an included study. A total of 37 studies were considered for possible inclusion during this process.

\subsection{Inclusion and exclusion criteria}

To be included in this review, a study had to meet two inclusion criteria. First, the study included at least one participant diagnosed with autism, Asperger syndrome, or pervasive developmental disorder-not otherwise specified (PDD-NOS). 
Second, the study evaluated an intervention that was aimed at teaching the participants to ask questions verbally or by using some form of augmentative and alternative communication (AAC) system or device (e.g., picture exchange or speech generating device). Studies in which data exclusive to question-asking could not be disaggregated from other dependent variables were excluded (e.g., Charlop, Gilmore, \& Chang, 2009). These criteria were determined prior to beginning the systematic search in order to reduce potential bias regarding study inclusion. Ultimately, 21 studies were identified for inclusion.

\subsection{Data extraction}

The 21 included studies were summarized in terms of the following features: (a) participant characteristics, (b) dependent variables, (c) intervention procedures, (d) research design, and (e) intervention outcomes. Because all of the included studies used single-case research designs (Gast, 2010), visual analysis of graphed data was used to assess outcomes.

\subsection{Reliability and inter-coder agreement}

To ensure accuracy in the application of inclusion criteria, the 37 studies that resulted from the systematic search, and the initial application of the inclusion criteria, were independently examined by two co-authors. Agreement as to whether a study should be included or excluded was obtained for 35 out of the 37 studies (95\%). A third author then reviewed the two studies on which there was initial disagreement. This trio then discussed the disputed articles until a consensus was reached.

After the final list of included articles was agreed upon, each study was coded in terms of (a) participant characteristics, (b) dependent variable, (c) intervention procedures, (d) research design, and (e) outcomes. To ensure the accuracy of these summaries, co-authors not involved in the initial data extraction/summary used a checklist to evaluate inter-coder agreement. The checklist included five questions regarding each study's summary: (a) Is this an accurate description of the participants? (b) Is this an accurate description of the intervention procedures? (c) Is this an accurate description of the dependent variables? (d) Is this an accurate description of the research design? and (e) Is this an accurate description of the outcomes? Co-authors were asked to read the study and summary, and then complete the checklist. In instances in which the summary was not considered accurate, the co-authors edited the summary to improve accuracy. This process continued until $100 \%$ agreement was reached on all summaries. Table 1 was created from the resulting summaries.

\section{Results}

Table 1 summarizes each of the 21 included studies.

\subsection{Participants and intervention settings}

Collectively, the 21 studies provided intervention to a total of 62 participants with ASD. Fifty participants were male ( $81 \%)$ and 12 female (19\%). This is consistent with the male to female ratio within the ASD population (American Psychiatric Association, 2000). Thirty-six of those participants (58\%) had a diagnosis of autism, 1 had an additional diagnosis of cerebral palsy; 1 participant (2\%) had a diagnosis of PDD-NOS; and the remaining 25 participants (40\%) were described as having ASD, with no specific diagnosis given. The ages of the participants ranged from 2 years 9 months to 25 years ( $M=7$ years, 9 months old). Of the studies that reported level of intellectual functioning, four participants (6\%) had an intellectual disability (ID), but the level of ID was not reported for these participants. For the participants in 17 studies (81\%) the level of intellectual functioning was not reported.

Intervention was implemented in various settings. School settings were used in $52 \%$ of studies $(n=11)$ (e.g., Betz, Higbee, \& Pollard, 2011; Ostryn \& Wolfe, 2011a; Williams, Perez-Gonzalez, \& Vogt, 2003). Clinic settings accounted for 9\% of reviewed studies $(n=2)$ (Koegel, Koegel, Green-Hopkins, \& Barnes, 2010; Palmen, Didden, \& Arts, 2008). Participant homes were used in 19\% of the reviewed studies $(n=4)$ (Esbenshade \& Rosales-Ruiz, 2001; Marion, Martin, \& Yu, 2011; Roy-Wsiaki, Marion, Martin, \& Yu, 2010; Williams, Donley, \& Keller, 2000). One study was conducted at a summer camp (Hung, 1977), and one employed an intervention during an after-school program (Charlop \& Milstein, 1989). More than one setting was used in $9 \%$ of studies $(n=2)$ to assess generalization across settings (Koegel, Camarata, Valdez-Menchaca, \& Koegel, 1998; Koegel et al., 2003).

\subsection{Dependent variables}

Various forms of questions (i.e., dependent variables) were targeted throughout the reviewed studies. What questions were taught in $48 \%$ of studies ( $n=10$ ), making them the most common dependent variable (e.g., Hung, 1977; Koegel et al., 2003; Marion et al., 2011; Taylor \& Harris, 1995). Where questions comprised 29\% of reviewed studies $(n=6)$ (e.g., Endicott \& Higbee, 2007; Koegel et al., 2010; Lechago, Carr, \& Grow, 2010).

In $38 \%$ of reviewed studies ( $n=7$ ), multiple question forms were targeted (e.g., Endicott \& Higbee, 2007; Ostryn \& Wolfe, 2011b; Shillingsburg, Valentino, \& Bowen, 2011). For example, Ostryn and Wolfe (2011b) taught participants to expressively 
Table 1

Summary of included studies.

\begin{tabular}{|c|c|c|c|c|}
\hline Citation & $\begin{array}{l}\text { Participant } \\
\text { characteristics }\end{array}$ & $\begin{array}{l}\text { Dependent variables invol-I } \\
\text { ving question-asking }\end{array}$ & -Intervention procedures & Research design and outcomes involving asking questions \\
\hline $\begin{array}{l}\text { Betz et al. } \\
\text { (2010) }\end{array}$ & $\begin{array}{l}2 \text { males, ages } 3: 5 \\
\text { and } 5 \text { years old, } 1 \\
\text { female, age } 4: 5 \\
\text { years old, all with } \\
\text { ASD }\end{array}$ & $\begin{array}{l}\text { Percentage of independent } \\
\text { mands for information using a } \\
\text { "Where + [item name]?" per t } \\
\text { session }\end{array}$ & $\begin{array}{l}\text { Trials began with } 30 \text { s access to a toy identified via preferencel } \\
\text { assessment. The toy was then hidden from the participant by } \\
\text { the therapist and the verbal discriminative stimulus, "Let's } \\
\text { play. Get [item]" was given. Echoic prompts and a 5-s time } \\
\text { delay procedure were used to elicit "Where [item]?" from } \\
\text { participants. Generalization probes were conducted with novelr } \\
\text { toys in the training setting, novel toys in a novel setting, andi } \\
\text { within a natural behavior chain with no specific verbal } \\
\text { discriminative stimulus. }\end{array}$ & $\begin{array}{l}\text { eResearch design: Multiple baseline across participants. } \\
\text { yOutcomes: All } 3 \text { participants acquired the initial skill } \\
\text { targeted, “Where [item]?", and demonstrated } \\
\text { generalization with novel toys in the training setting and } \\
\text { with novel toys in a novel setting. Generalization to a } \\
\text { anatural behavior chain did not occur until training using an } \\
\text { dinterrupted chain procedure was implemented. }\end{array}$ \\
\hline $\begin{array}{l}\text { Charlop and } \\
\text { Milstein } \\
\text { (1989) }\end{array}$ & $\begin{array}{l}3 \text { males, ages } 6: 10,1 \\
7: 6, \text { and } 7: 10 \text { years } \\
\text { old, all with ASD }\end{array}$ & $\begin{array}{l}\text { Number of appropriate } \\
\text { squestions }\end{array}$ & $\begin{array}{l}\text { Video modeling was used to teach scripted conversations } \\
\text { about preferred toys. The participant was shown a videotaped } \\
\text { conversation } 3 \text { times. Therapist said, "Let's do the same," andr } \\
\text { paused before providing the first line of conversation. If } \\
\text { criterion was not met, the video was shown again and the childg } \\
\text { was tested afterward. During probes, child and therapist heldd } \\
\text { the same toys as in the video. Correct responses were } \\
\text { acknowledged, questions were answered, and access to } \\
\text { requested toys was provided. Reinforcement in the form of } \\
\text { edibles and verbal praise was provided for sitting still, } \\
\text { attending, and talking. }\end{array}$ & $\begin{array}{l}\text { Research design: Multiple baseline across participants, } \\
\text { dwithdrawal design embedded within participants, and } \\
\text { dmultiprobe across conversations. } \\
\text { Outcomes: All participants increased question-asking skills, } \\
\text { dgeneralization across people, settings, stimuli, and } \\
\text { dconversation topics was reported. Maintenance was } \\
\text { demonstrated at } 15 \text { months. }\end{array}$ \\
\hline $\begin{array}{l}\text { Endicott } \\
\text { and Higbee } \\
\text { (2007) }\end{array}$ & $\begin{array}{l}4 \text { males, ages } 3,4,4, \\
\text { and } 5 \text { years old, all } \\
\text { with ASD }\end{array}$ & $\begin{array}{l}\text { 4,(a) Percentage of correct } \\
\text { Imands for "Where?" and (b) i } \\
\text { Percentage of correct mands } \\
\text { for "Who?" }\end{array}$ & $\begin{array}{l}\text { Trials began by providing participants access to a preferred } \\
\text { item identified via preference assessment for } 30 \text { s. The item } \\
\text { was then hidden in one of } 3 \text { potential places while the } \\
\text { participant was not looking. The participant was then told tol } \\
\text { "Get [item]". After an incorrect or no response, an echoic } \\
\text { prompt "Say, "Where [item]?"' was given. Contingent on } \\
\text { correct mand the instructor gave the location of the missing } \\
\text { item and } 30 \text { s of access to the item was provided following } \\
\text { retrieval. In a second phase identical procedures were used } \\
\text { except the item was given to another person and the } \\
\text { participant was prompted to ask, "Who has [item]?" }\end{array}$ & $\begin{array}{l}\text { Research design: A multiple baseline across participants } \\
\text { with a generalization phase was used for each dependent } \\
\text { variable. A multielement design within each multiple } \\
\text { obaseline evaluated the intervention using high-preferred } \\
\text { and less-preferred items. } \\
\text { Outcomes: All participants acquired the mand "Where } \\
\text { [item]?" for highly preferred items and } 2 \text { of the } 3 \\
\text { participants acquired this mand for low-preferred items. } \\
\text { Two participants generalized where questions from clinic to } \\
\text { home. All } 3 \text { participants acquired the mand "Who has } \\
\text { [item]?" for high- and low-preferred items. }\end{array}$ \\
\hline
\end{tabular}

(2001) known items therapist. If the child did not respond correctly within $5 \mathrm{~s}$, theOutcomes: The number of questions asked when presented therapist delivered the vocal model prompt "Say, What is with unknown items increased during all tasks with the that?" The child was praised and given information about theexception of the generalization task in which the name of the item contingent upon correct imitation of "What isparticipant was told to "Give this to [person's name]." that?". Generalization across different instructional tasks wasFollowing inclusion of programming common stimu assessed using the variations of the discriminative stimulus across tasks, generalization occurred for all tasks. and across caregivers. If generalization did not occur after the initial training procedures, programming common stimuli was used to facilitate generalization. 
Hung (1977) 2 males, ages 9:2 (a) Daily frequency of the Participants were shown picture cards of nouns and verbs andResearch design: Classroom training was evaluated within a and 10:8 years old questions "What is/are and 1 female, age [object name for

8:1 years old; all "What is/are [name of target questions about objects and cards. During scheduled Outcomes: All participants learned to ask questions in the occasionally real objects in a classroom setting of a summer pre-experimental AB design and generalization was with autism (child person] doing?" and (b) Meansessions and outside of the classroom, spontaneous questionsclassroom training setting. However, participants did not with schizophrenia spontaneous questions (i.e., were reinforced with praise, tokens (token exchange rate wasspontaneously ask questions outside of the classroom until was excluded) no prompt within previous also systematically manipulated), or edibles plus answers to the token value was increased. During maintenance, the 2 30 s) per hour during non- questions. Repetitious questions received only praise. participants were not receiving tokens and asked no

training times Generalization training involved the same reinforcement andquestions.

least-to-most prompting and was conducted in a more natura setting within the classroom. Follow-up data on questionasking were collected at 11 months without additional classroom training for 2 of the 3 participants.

Ingvarsson and 4 males, ages 4, 6, 7,Number of times participantsPretest with 56 questions was administered to create lists of Research design: Nonconcurrent multiple baseline across Hollobaugh and 10 years old, allmanded for information

(2010) with autism using the phrase, "I don't questions for which participants knew the answer (known) participants.

$\begin{array}{lll}\text { know. Please tell me." } & \text { (unknown). A set of unknown questions was targeted. Echoicanswers to questions. Two of the participants }\end{array}$ prompts and time delay were used to teach the phrase whichthe phrase across questions. The other 2 participants functioned as a mand for information. For 2 participants, edibleacquired the phrase after edibles were added. Overall reinforcers were used, and for 1 of those 2 participants, generalization probes yielded mixed results, but some form gradually faded.

Koegel et al. $\quad 2$ males, ages 3:11 Number of times the child and 5:4 years old, spontaneously asked, and 1 female, age "What's that?" 3:9 years old, all with autism

Preferred items were put in an opaque bag and the of generalization was demonstrated for all 4 participants.

Research design: Multiple baseline across participants. participants were taught to ask, "What's that?" using an echoicOutcomes: All 3 participants increased spontaneous asking. prompt. Questions were reinforced with access to the item and"What's that?", during intervention. All participants the answer. After the child spontaneously asked, "What's generalized across settings (home) and to new stimuli that?" consistently over several sessions, less preferred items(novel items). were used. Generalization probes were conducted under 2 conditions (a) in response to new items in the clinic while the child engaged in play/social interactions with a clinician and (b) in response to new items at the child's home while the child engaged in play/social interaction with his/her mother.

Koegel et al. 2 males, ages 4:4 Child 1: (a) Number of Participants were taught to use a self-initiated query ("What Research design: Multiple baseline across participants. (2003) and 6:3 years old, occurrences of regular past happened?" or "What's happening?") using pop-up books andOutcomes: Participants improved on all dependent both with autism tense verb productions, (b) vocal model prompting. After the participant asked the measures. Generalization to other question forms was both with autism tense verb productions, (b) vocal model prompting. After the participant asked the measures. Gen
Number of productions of question, the clinician responded with the appropriate verb demonstrated. Number of productions of question, the clinician respond
"What happened?", and (c) stem-plus-temporal morpheme.

Percentage of correct

responses using regular past

tense.

Child 2: (a) Number of

occurrences of present

progressive verb productions,

(b) Number of productions of

"What's happening?", and (c)

Percentage of correct

responses using the present

progressive 
Koegel et al. 3 males, ages 3:2, Percentage of unprompted Preferred items (e.g., candy or toys) were hidden. ParticipantsResearch design: Multiple baseline across participants.

"Where is it?" questions per were prompted to ask "Where is it?" with an echoic prompt.Outcomes: All 3 participants increased their questionold, all with autismsession and of unprompted The clinician responded to questions with a targeted asking from $0 \%$ to an average of $85-99.7 \%$ during

correct prepositional/ordinal preposition (e.g., on the table, under the doll, etc.). Echoic

$$
\text { markers }
$$
prompts were then faded. Approximately every 5 th intervention session, pre-session probes assessed if the participant had acquired a preposition as an expressive language structure. The clinician asked the child, "Where is the [item]?" to probe this skill.

Lechago et al. 3 males, ages $4: 6$, Cumulative number of (2010) 4:6, and 7 years old,correct mands for all with autism information: "Where spoon?" or "Who has spoon?" or "Who has [the spoon?"

Participants were taught behavior chains for a specific task (i.e.,Research design: Nonconcurrent multiple baseline across making a baking soda volcano) using total task presentation. participants.

An interrupted-behavior-chain procedure was then used to Outcomes: All 3 participants acquired the target skill and establish motivation for information. Vocal model prompts generalized the response across the activities. For 2 were used to teach the mands "Where spoon?" or "Who has participants, the question generalized to asking for [the] spoon?" during the activity interruptions. Mands that information using an untaught noun (i.e., truck). occurred within $10 \mathrm{~s}$ of interruption were reinforced with information. The participant learning the where mand was given information regarding the location of the spoon (e.g., "It's in the green drawer"). The 2 participants learning the who mand were given information related to an instructor wearing a colored shirt (e.g., "Blue has the spoon"). A $2 \mathrm{~s}$ time delay was used before delivery of an echoic prompt for the targeted mand. Other behavior chains (e.g., making flavored milk, setting a table) were used to probe for generalization across establishing operations.

Marion et al. 3 males, ages 5:7 Correct use of the question (2011) 8:5 (with ASD), and“What is it?" 4 years old (with autism)

Research design: Multiple baseline across situations and Motivating situations involving: hide and seek, missing items,activities that motivated questions for each participant. requiring more of something, and telling the participant thatOutcomes: All 3 participants acquired the skill for each there was a surprise were contrived for each activity and vocalmotivating situation and activity and generalized to the and non-vocal scripts, designed to elicit the question, were natural environment and a novel activity. Maintenance at 4 created for each situation. An echoic prompt (i.e., "Say, "What isweeks was demonstrated. it?"') was faded using a progressive time delay and the intensity of the prompt (i.e., partial echoic prompts). Provision of the requested information related to continuation of the activity was contingent on correct questions. Trials were presented again following errors.

Ostryn and 1 male, age 4 yearsIndependent correct use of Wolfe (2011a) old with PDD-NOS, “What's that?", initially 2 females, ages 3 communicated by pictures and 4 years old, and then vocally both with ASD containing items and modeled the

Research design: Multiple baseline across participants. "What's that?" question, then waited $2 \mathrm{~s}$ for participants to Outcomes: All 3 participants learned to ask "What's that?". imitate before using most-to-least prompting for the picture Generalization occurred for all participants across stimuli, exchange. Contingent upon questions, participants were told people, and settings. Maintenance was demonstrated for the name of the item. After the participant requested the itemparticipant at 3 months and 2 participants at 6 months. $\mathrm{s} /$ he was given access to it. Pictures were faded. Two of the participants began echoing the prompt, and least-to-most prompting with vocal model prompts was implemented. The third participant's response was changed to a verbal approximation and gesture. 
Citation Participant

characteristics

Dependent variables invol-Intervention procedures

ving question-asking

Ostryn and 1 male, age 3:5

Correct and unprompted

Preference assessments were conducted to determine

Research design and outcomes involving asking questions

Research design: Multiple baseline across participants.

Wolfe (2011b)years old, and 2 utterance of "What's that?" preferred items. An item was placed in a bag and participantsOutcomes: All 3 participants learned to ask both questions females ages 4:2 or "Where is it?" in which thewere prompted to ask, "What's that?" using an echoic promptand to discriminate when to use each question.

and 4:11, all with participant had to determinewith a $2 \mathrm{~s}$ time delay. Contingent on target response, ASD

which question was participants were shown the item and given information about appropriate for the context it (e.g., name of item, color, size, sounds it made). When the participant requested the item or responded to the question "Would you like to see it?" or "Would you like to play with it/ have it?", $20 \mathrm{~s}$ of access was allowed. To teach "Where is it?", participants were presented with a container and directed to "Get your [item]", then had free access to the item. Next, the access to the item. Next, the investigator covertly removed the item, presented the empty container, and said, "Get your [item]." An echoic prompt was used to teach, "Where is it?" After each teaching session, a discrimination session involving both questions with no prompting was implemented.

7 males and 2

Percentage of correct

Groups of 3 participants received sessions involving questions during a tutorial introduction (aim of training explained), evaluation of

age $=19$, range 17-conversation and response simulated conversations, and role play/table game. A flow years old), all efficiency; specifically, with high

chart was used during int provide corrective feedback. Least-to-most prompting was

functioning ASD correct if they were (a) askedused during the correction procedure (indirect verbal

Research design: Nonconcurrent multiple baseline across 3 groups of 3 participants.

Outcomes: Percentage of correct questions increased for al correct if they were (a) askedused during the correction procedure (indirect verbal
within $5 \mathrm{~s}$, (b) were related toinstruction, direct verbal instruction, and finally modeling

the topic of conversation, andcorrect response). Participants earned points for correct

(c) began with an questions asked during the table game, which could later be

interrogative or a verb exchanged for prizes.

Roy-Wsiaki 1 male, age 5 yearsPercentage of correct Four activities (hide and seek, missing item needed for task Four activities (hide and seek, missing item needed for question "What?" were contrived during sessions. Scripts wereOutcomes: Use of "What?" increased during all 4 activities used as verbal discriminative stimuli to elicit the question. and generalized to untrained scripts, settings, and novel Scripts included statements such as: "Let's add something,", "Iactivities. Results maintained at 1, 2, and 4 weeks. put something away," and "I brought you something." Training consisted of prompting the response using an echoic promp that was faded with partial vocal models and a progressive time delay. Contingent on the question "What?" information and the missing or needed item required for the activity was provided. et al. (2011) and 11:11 years "Who," "Which," an old, both with with con Preference assessments were used to determine preferred Research design: Multiple probe across questions. items. Four activities designed to motivate the question wereOutcomes: Both participants learned to ask 3 different "When" for the other contrived during sessions for each question taught. As a the antecedent manipulation, nonverbal and verbal discriminative stimuli were presented. For example, 3 therapists were present and the participant was told "Some procedure (moving from only non-verbal and verbal training. Both dependent variables for all participants time delay was used to teach the question. questions (e.g. wh acquired, generalization of a specific question did occur neacross situations. One participant maintained all questions, with last question probed at 18 days. The other participant was assessed for maintenance between 4 and 10 weeks and $\mathrm{s}$ all questions were maintained except for 2 scenarios involving where. 
Shillingsburg 1 male, age 7:8 and Valentino years old with (2011) autism unplugged computer monitor and batteries missing from increased across all 6 activities and generalized across remote). The participant selected a specific activity for each activities after the first two were directly taught. session. An echoic prompt was immediately presented on the first trial each session. Subsequent trials included a $5 \mathrm{~s}$ time delay to allow an independent response. Contingent on independent asking of "How?" information regarding how to complete the activity and access to the preferred activity was complete
provided. (2002) males, ages 5 and 6 correct use of "Wher" Experiment 1: Two sets of items (one reinforcing set and one Research design: Multiple baseline assessed performance
neutral set) were chosen for each participant. Two items (oneacross questions and a multielement design compared years old, both withExperiment 2: Correct and from each group) were chosen and placed in 1 of 3 containerspreferred item to neutral item set within each participant. A autism. incorrect use of "Where?" (a box, bag, or can). Participants were told, "Get your [item]"multiple baseline across participants also evaluated the Experiment 2: and "Who?" and, in the last 2allowed brief contact with the item, then distracted. During theintervention.

Participant 1 from sessions, the latency betweendistraction activity, the item was placed in 1 of the other 2 Outcomes Experiment 1: Both participants increased use of experiment 1 (age 5the final word in the verbal containers. Then the participant was presented with an emptyquestions about the location of items. For Participant 1 , the year old) and stimulus, "I gave it to a container and told, "Get your [item]." Echoic or imitative (sign)preferred item question was acquired first. For Participant another male, age 8teacher" and the question prompts were used and faded using partial prompts and time2, the less preferred item question was acquired more years old, with being directed to the correct delay. Correct responses were followed by the information ofquickly. Participant 1 asked about location of preferred autism. teacher. the location of the item. items without training, but did not do so with neutral items. Expenime 2. The same procedures for Experiment 1 were inParticipant 2 did not generalize across item sets. place except, when the participant asked, “Where [item]?”, theOutcomes Experiment 2: Both participants learned to ask, experimenter responded with "I gave it to a teacher". One of 3"Who has it?", with similar results for both preferred and teachers in the room had been covertly given the item. The non-preferred items. Both participants showed a shorter reinforced with the requested information. and the question "Who has it?" for desired items than for undesirable items.

Maintenance was probed for 1 participant and skills were maintained at 6 months.

Taylor and 2 males, ages 5 andPercentage of correct Pretests classified pictures that participants could and could Research design: Multiple baseline across participants.

Harris (1995) 9 years old, and 1 independent asking “What's not expressively identify. During intervention, 4 pictures wereOutcomes: All participants learned to ask, "What's that?", female, age 9 yearsthat?" while pointing to an placed on a table. The instructor said, "Tell me what you see onwhen presented with unknown pictures and while on a old, all with autismunknown stimulus

the table." Participants were taught to label pictures from leftwalk and generalized the skill to unknown objects in the

to right. When the participant pointed to an unknown picture,school kitchen with a different adult.

the experimenter vocally modeled, "What's that?", in an

exaggerated questioning tone of voice. Contingent on

imitation, the item label and a tangible reinforcer were given. After the child imitated "What's that?" for 3 consecutive trials, the experimenter increased the time delay from 0 to $2 \mathrm{~s}$. Physical prompts to occasion pointing were used and then gradually faded. Time delay was further faded to $10 \mathrm{~s}$.

Participants were then taught to ask, "What's that?", while on a walk around the school. When they approached a novel object, the experimenter paused approximately $1 \mathrm{~m}$ from the object for $1 \mathrm{~s}$ to assess whether the child would point and ask, "What's that?". Prompting was provided using a gradual, progressive time delay. 
Citation

Participant

characteris

Dependent variables invol-Intervention procedures

Research design and outcomes involving asking questions

Williams 2 females, both ageFrequency of asking "What's The experimenter held a box and commented about an objectResearch design: Multiple baseline across questions.

et al. (2000) 4 years old, both that?" "Can I see it?", and inside. The participant was prompted to ask, "What's that?", Outcomes: Both participants learned to ask all 3 questions with autism

using echoic prompts. The box and object were given

and generalized the skills across people (i.e., to mothers)

contingent on asking. Prompts were gradually faded, and whenand setting (i.e., living room). Skills maintained at 20 days

the participant initiated the question independently, trainingfor participant 1 and 11 months for participant 2 .

on the next question form began. During training on the secon

response, the experimenter told the child the name of the

object when she asked, "What's that?", but did not give the

box. Next, "Can I see it?" was targeted, and access to the box

and item was again made contingent. Finally, "Can I have it?"

was targeted and the other two questions only produced the

name and sight of the item, while only the final target question

resulted in access to the box

Williams $\quad 3$ males, ages 2:9, Frequency of asking "What's First, the procedures described in Williams et al. (2000) wereResearch design: Multiple baseline across participants with 4:5, and 9:4 years in the box?", "Can I see it?" implemented and all participants acquired all 3 questions. each of phases presented in procedures presented in orde old, all with autismand "Can I have it?" on, "Can I see it?", the experimenter said, "No!", and the boxending with some unpleasant objects for participant 3 was only given if the participant asked, "Can I have it?", (b) theduring the final phase.

experimenter hid the box behind her back and the same Outcomes: All participants learned to ask all 3 questions in contingencies remained in place, (c) prompts were stopped the first teaching phase. The purpose of the subsequent and the original contingencies were reinstated. If the phases was to determine how differing consequences participant only asked, "What's in the box?", then "Can I havewould affect the relative rate of specific questions. Results it?" he was told, "Sure, you can have it", and given the box, (d) 5suggest that each question was maintained by different out of 10 trials randomly contained non-preferred objects, (e)contingencies and can be classified as independent all trials contained unpleasant objects, and (f) the participantrepertoires of behavior.

was told "No!" to the question "Can I have it?" but was told

"Sure!" and given the box contingent on the question "Can I see it?" 
discriminate between "What's that?" and "Where is it?" Further, Williams et al. (2000, 2003) employed interventions targeting the questions: "What's in the box?", "Can I see it?", and "Can I have it?"

Both where and who questions were targeted in $14 \%$ of the reviewed studies $(n=3)$ using two separate experiments. Specifically, after participants acquired the where question during the first experiment, a second experiment was conducted in which the who question was taught (Endicott \& Higbee, 2007; Lechago et al., 2010; Sundberg, Loeb, Hale, \& Eigenheer, 2002).

Shillingsburg et al. (2011) was the only study included in this review that involved instruction on four different whquestions: who, which, where, and when. Moreover, Shillingsburg and Valentino (2011) targeted a how question. Finally, Ingvarsson and Hollobaugh (2010) taught the mand for information: "I don't know. Please tell me." As such, this is the only study in this review that taught a mand for information that was not technically [grammatically] a question, but it does serve the same function as a what question (i.e., the participant is told the name of an object as reinforcement).

\subsection{Intervention procedures}

All of the included studies implemented a multicomponent behavioral intervention. All 21 studies applied systematic prompting and prompt fading procedures (e.g., time delay). The most common type of prompt was a vocal model, or echoic prompt, which was used in 95\% $(n=20)$ of the studies (e.g., Endicott \& Higbee, 2007; Marion et al., 2011; Shillingsburg et al., 2011). Other prompts included a video model (Charlop \& Milstein, 1989), a picture exchange model (Ostryn \& Wolfe, 2011a), indirect and direct verbal instructions (Palmen et al., 2008), and an imitative/sign model (Sundberg et al., 2002).

Different forms of reinforcement were used throughout the studies. Provision of information (i.e., the answer to the question) was the natural consequence that was hypothesized to function as reinforcement in all reviewed studies. Additionally, $91 \%$ of studies $(n=19)$ included supplementary [contrived] reinforcement in the form of access to a preferred item/activity/edible or tokens/points paired with contingent information. The most common supplementary reinforcement was either access to an item or continuation of an activity related to the question, which was applied in $67 \%$ of studies $(n=14)$ (e.g., Betz et al., 2010; Marion et al., 2011; Shillingsburg \& Valentino, 2011). Edible reinforcement was used in 19\% of studies $(n=4)$ (Charlop \& Milstein, 1989; Hung, 1977; Ingvarsson \& Hollobaugh, 2010; Taylor \& Harris, 1995). Tokens or points, which could be exchanged for backup reinforcers, were used in $14 \%$ of studies $(n=3)$ (Hung, 1977; Palmen et al., 2008; Taylor \& Harris, 1995).

A commonly employed intervention strategy was to contrive an establishing operation (EO), wherein motivation for asking questions was created within the context of an activity; $67 \%$ of reviewed studies $(n=14)$ used this type of EO technique (e.g., Betz et al., 2010; Koegel et al., 1998; Shillingsburg et al., 2011). Specifically, to contrive an EO for participants to ask questions, the teaching environment was often strategically arranged by hiding highly preferred or interesting items in containers or with the instructor. Contingent upon the participant asking a where question, information regarding the location of the missing item was provided (e.g., Betz et al., 2010; Endicott \& Higbee, 2007; Sundberg et al., 2002).

Verbal discriminative stimuli in the form of scripts (e.g., "I hid something”) or directives (e.g., "Get your [item name]") were used to set the occasion for a question in $48 \%$ of studies $(n=10)$ (e.g., Marion et al., 2011; Shillingsburg \& Valentino, 2011; Sundberg et al., 2002). Marion et al. (2011) taught participants to ask, "What is it?" using scripts as discriminative stimuli. For example, during an activity designed to motivate the child to ask, "What is it?", the instructor used a script in which the phrase, "Oh no!" was intended to set the occasion for the target response. Specifically, while making a model volcano, only a small amount of vinegar was provided, and the volcano failed to erupt. The instructor said, "Oh no!" with her hands and palms up, and the participant asked, "what is it?" The instructor then provided the information required to continue the activity (i.e., "We need more vinegar."), and the activity resumed.

An interrupted behavior chain procedure was used in 10\% of studies ( $n=2$ ) (Betz et al., 2010; Lechago et al., 2010). Participants were taught to ask where or who questions during a multi-step behavioral sequence (chain) with one critical stimulus missing. For example, the participant was told, "It's time to color," then walked to a shelf and retrieved paper and a crayon box and sat down at the table. When she opened the box, the crayons were missing, which was intended to create the need for a where question (Betz et al., 2010).

Discrete trial training was implemented in 33\% of studies $(n=7)$ (e.g., Esbenshade \& Rosales-Ruiz, 2001; Ingvarsson \& Hollobaugh, 2010; Taylor \& Harris, 1995). For example, participants were presented with a discriminative stimulus $\left(S^{\mathrm{D}}\right)$ and taught to request information (e.g., "What's that?"). The delivery of information served as positive reinforcement. Other intervention components utilized include video modeling (Charlop \& Milstein, 1989) and small group social skills instruction (Palmen et al., 2008).

\subsection{Research design}

All of the studies used single-case research designs (Gast, 2010). Multiple baseline designs were used in 59\% of studies ( $n=13$ ) (e.g., Esbenshade \& Rosales-Ruiz, 2001; Palmen et al., 2008; Shillingsburg \& Valentino, 2011), multiple probe designs were used in $5 \%$ of studies $(n=1)$ (Shillingsburg et al., 2011), a non-concurrent multiple baseline was used in $14 \%$ of studies $(n=3)$ (Ingvarsson \& Hollobaugh, 2010; Lechago et al., 2010; Palmen et al., 2008), and 23\% of the studies ( $n=5$ ) used a combination of research designs (e.g., Charlop \& Milstein, 1989; Sundberg et al., 2002, Experiment 1; Sundberg et al., 2002, Experiment 2). In all of the studies, interobserver agreement (IOA) data were collected, and the reported IOA percentages 
were on average greater than $80 \%$. Finally, procedural integrity checks were conducted in $27 \%$ of studies ( $n=6$ ) with $80 \%$ or greater integrity reported (e.g., Betz et al., 2010; Lechago et al., 2010; Marion et al., 2011).

\subsection{Outcomes}

While all of the reviewed studies reported positive outcomes with regard to acquisition of question-asking skills, generalization effects were mixed. Various generalization measurements were collected in $81 \%$ of the reviewed studies ( $n=17$ ) (e.g., Hung, 1977; Shillingsburg et al., 2011; Williams et al., 2000). These included assessing generalization across (a) instructional stimuli, (b) settings, (c) people (i.e., conversation partners), and (d) time (i.e., maintenance).

Effects of generalization across instructional stimuli in the form of materials, activities, or tangible items were measured in $62 \%$ of the reviewed studies $(n=13)$ (e.g., Koegel et al., 1998; Lechago et al., 2010; Roy-Wsiaki et al., 2010). Nine of those studies reported positive results (e.g., Lechago et al., 2010; Roy-Wsiaki et al., 2010; Sundberg et al., 2002). Generalization across settings was measured in $53 \%$ of studies $(n=11)$, and positive results were reported by 10 of those studies (e.g., Endicott \& Higbee, 2007; Koegel et al., 1998; Taylor \& Harris, 1995). Generalization across people (i.e., conversation partners) was measured in $38 \%$ of studies $(n=8)$ (e.g., Charlop \& Milstein, 1989; Esbenshade \& Rosales-Ruiz, 2001; Williams et al., 2000). Positive results regarding generalization across people were reported by five studies (Endicott \& Higbee, 2007; Koegel et al., 1998; Ostryn \& Wolfe, 2011a; Taylor \& Harris, 1995; Williams et al., 2000).

Maintenance probes, ranging from six days to 15 months ( $M=16$ weeks), were collected in $43 \%$ of the reviewed studies ( $n=9$ ) (e.g., Charlop \& Milstein, 1989; Roy-Wsiaki et al., 2010; Shillingsburg et al., 2011). Only one study reported negative results during follow-up (Hung, 1977).

\section{Discussion}

We identified and summarized 21 studies that involved teaching question-asking skills to individuals with ASD. The approaches to intervention in these studies shared several common components. Specifically, those components included: (a) ensuring participants are motivated to ask questions by identifying preferred items and/or activities and strategically arranging the instructional environment (i.e., contriving EOs), (b) using information and access to preferred items or activities as positive [natural] reinforcement for question-asking, and (c) using systematic prompting and prompt fading (e.g., time delay). Each of these components is discussed in more detail below.

Ensuring the presence of a motivating EO is generally considered to be essential for effectively training individuals with ASD to ask questions (Hartman \& Klatt, 2005; Sundberg \& Michael, 2001; Sundberg \& Partington, 1998). Across the reviewed studies, several procedures were used to ensure the participants were motivated to ask questions. One approach simply involved selecting a time and or place that was likely to evoke question-asking. For example, someone who has not eaten recently is likely to be more motivated to ask questions about the availability of food (e.g., When is dinner?) than someone who has just eaten a meal and is not in an environment where food is typically served (Langthorne \& McGill, 2009). A second way to ensure motivation might be to use items and activities in the intervention that the participant prefers. For example, it may be easier to teach a child with ASD to ask the question "Where is my stuffed bear?" if the stuffed bear is a preferred item, but the child does not have possession of the bear (i.e., the toy bear is missing). In most of the reviewed studies systematic preference assessments were used to identify stimuli and activities likely to function as reinforcers. Marion et al. (2011) used a parent questionnaire to identify participants' preferences, which were then incorporated into different activities. Other studies employed direct preference assessments involving observation of participants' interactions with items to determine which items they preferred (e.g., Betz et al., 2010; Endicott \& Higbee, 2007; Sundberg et al., 2002). Finally, motivation was established via environmental arrangement. For example, preferred items were hidden in the environment to motivate where questions.

Reinforcement in the form of providing answers to questions (e.g., telling the child the location of a preferred item or information related to continuation of a preferred activity) was used in all of the reviewed studies. However, several of the studies emphasize the importance of pairing answers with some form of contrived (tangible) reinforcement to facilitate initial skill acquisition (e.g., Betz et al., 2010; Lechago et al., 2010; Marion et al., 2011). For example, tokens or edibles might be given in tandem with answers to provide additional reinforcing consequences for the target behavior. It is important to note that, while the addition of tangible reinforcers might facilitate acquisition, the use of such contrived reinforcement might also hinder generalization if these contrived reinforcers are not typically available in the natural environment and are not faded during the intervention process (Skinner, 1982; Stokes \& Baer, 1977). It would also seem important for the participants with ASD to have sufficient receptive language skills (i.e., an adequate listener's repertoire) to act on the answers they receive.

All of the reviewed studies also implemented systematic prompting and prompt fading procedures to teach target questions. The most common type of prompt was an echoic prompt, which involved the therapist demonstrating or modeling the question for the participant (e.g., Endicott \& Higbee, 2007; Marion et al., 2011; Shillingsburg et al., 2011). At first participants are reinforced for prompted questions, but gradually response requirements are increased and prompts are faded so that participants must ask questions with less support from the therapist. Various prompt fading procedures were applied across studies. However, most studies implemented some form of a time delay procedure. Time delay procedures involve waiting a predetermined amount of time before delivering a prompt (e.g., Esbenshade \& Rosales-Ruiz, 2001; Ostryn \& Wolfe, 2011b; Shillingsburg et al., 2011). A second approach to prompt fading involved varying the length or intensity of the prompt. For example, a therapist might begin by providing a complete vocal model (e.g., "What is it?"'), but then reduce 
the length of the vocal model ("What. ..") in conjunction with a time delay (e.g., Marion et al., 2011; Roy-Wsiaki et al., 2010; Sundberg et al., 2002). The participant is first expected to imitate the full model and then as the length of model decreases the participant fills in the missing parts of the question independently until the therapist no longer needs to model any portion of the question. The current literature provides evidence that echoic prompting and systematic prompt fading procedures, such as a time delay, are effective components of question-asking interventions.

In addition to improvements in question-asking skills, these interventions were also sometimes associated with gains in other related skills. For example, several studies demonstrated that after an individual had been taught to ask for the name of an unknown item they then used this name for expressive labeling. In other words, some individuals appeared to be able to learn new information from the answers to the questions they asked during intervention (e.g., Esbenshade \& Rosales-Ruiz, 2001; Koegel et al., 1998; Taylor \& Harris, 1995). Additionally, teaching individuals with ASD to ask questions appeared to reduce problem behavior in some cases. For example, Ingvarsson and Hollobaugh (2010) taught participants to mand for information by saying, "I don't know. Please tell me," when presented with a difficult task. Acquisition of this mand could be associated with a reduction in problem behavior, perhaps because the task thus became less difficult. Future research should investigate if mands for information have an effect on challenging behavior during work tasks.

The research reviewed here suggests that people with ASD can be taught to ask questions and that learning to ask questions might facilitate the acquisition of other communication skills and impact on other areas of adaptive behavior functioning. However, the studies so far have tended to involve participants with speech. Only one study (i.e., Ostryn \& Wolfe, 2011a) used assistive technology (i.e., picture exchange communication system) to enable question-asking by nonspeaking participants. Given that AAC systems have been successful in supporting other communication and social skills for people with ASD (Ganz, Davis, Lund, Goodwyn, \& Simpson, 2012; van der Meer \& Rispoli, 2010), it seems likely that these might also enable nonspeaking participants to ask questions.

The most common questions taught in the reviewed studies were what and where questions. In typical language development, what and where questions appear before other question types (Bloom et al., 1982; Smith, 1933; Tyack \& Ingram, 1977). This parallel is not surprising when taking into account that the reinforcement of early what and where questions is often more closely associated with a child's environment, as what often yields names of new objects and where often reveals location of toys (Tyack \& Ingram, 1977). In comparison, why questions develop later and may be more difficult to teach because the answer (often the only reinforcing consequence in the natural environment) involves information that may not have as much of an immediate benefit as what and where questions. Therefore, additional research aimed at teaching why also appears necessary.

The research base is also limited in terms of the diversity of listeners for the participants' question-asking (e.g., teaching staff versus peers). Question-asking is ubiquitous in social conversation, it would seem to be necessary for research (a) to involve peers and unfamiliar listeners and (b) to include increased opportunities for social interaction with same-aged peers, decreased reliance on adult support in inclusive settings, and increased opportunities for generalization. Clearly, procedures designed to teach peer-directed questions are needed.

Although the acquisition outcomes were generally positive, generalization effects were somewhat limited. For example, while some studies reported positive results for generalization across instructional materials or activities (e.g., Betz et al., 2010; Endicott \& Higbee, 2007; Marion et al., 2011), other studies reported mixed results (e.g., Charlop \& Milstein, 1989; Esbenshade \& Rosales-Ruiz, 2001; Shillingsburg et al., 2011). Further, although Betz et al. (2010) successfully taught three participants the where mand and it generalized across novel toys and novel settings, the mand failed to generalize to a natural behavior chain. This may be due to the lack of a verbal $S^{D}$ (i.e., instructional cue), which was present during structured training sessions. Specifically, participants were taught to ask the question, "Where + [item name]?" after the therapist said, "Let's play. Get [item name]." When probed in a natural behavior chain, wherein the verbal $S^{D}$ was absent, the where question failed to generalize for all three participants. For example, in the "going for a walk outside" natural behavior chain, the participant was required to go to his backpack, retrieve his coat and hat, and line up at the door. This chain was interrupted by a missing hat, which would be the natural $S^{D}$ (i.e., nonverbal cue) to elicit the question, "Where hat?" However, Betz et al. (2010) found that all three participants required training via an interrupted-behavior-chain procedure for multiple natural behavior chains (e.g., coloring, bowling, Play-Doh activity) before generalization to other natural behavior chains was achieved. These findings suggest the need for more research aimed at understanding and facilitating the generalization of these questions.

In conclusion, the findings of this review suggest that systematic instructional procedures (i.e., contrived EO, prompting, and reinforcement) have been effective in teaching individuals with ASD to ask questions. However, future research should aim to extend the evidence-base by addressing research questions related to question-asking via assistive technology, directing questions to peers and other diverse listeners, teaching why questions, and supporting the generalization and maintenance of question-asking.

\section{References}

American Psychiatric Association. (2000). Diagnostic and statistical manual of mental disorders (4th ed., Text revision). Washington, DC: American Psychiatric Association.

Betz, A. M., Higbee, T. S., \& Pollard, J. S. (2010). Promoting generalization of mands for information used by young children with autism. Research in Autism Spectrum Disorders, 4, 501-508.

Bloom, A. M., Merkin, S., \& Wooten, J. (1982). Wh-questions: Linguistic factors that contribute to the sequence of acquisition. Child Development, 53, $1084-1092$. 
Brown, R. (1968). The development of wh questions in child speech. Journal of Verbal Learning and Behavior, 7, 279-290.

Brown, R., Cazden, C., \& Bellugi-Klima, U. (1969). The child's grammar from I to III. Minnesota Symposia on Child Psychology, 2, 28-74.

Charlop, M. H., Gilmore, L., \& Chang, G. T. (2009). Using video modeling to increase variation in the conversation of children with autism. Journal of Special Education Technology, 23, 47-66.

Charlop, M. H., \& Milstein, J. P. (1989). Teaching autistic children conversational speech using video modeling. Journal of Applied Behavior Analysis, 22, 275-285.

Chouinard, M. M. (2007). Children's questions: A mechanism for cognitive development. Monographs of the Society for Research in Child Development, 72, 1-112.

Duffy, C., \& Healy, O. (2011). Spontaneous communication in autism spectrum disorder: A review of topographies and interventions. Research in Autism Spectrum Disorders, 5, 977-983.

Endicott, K., \& Higbee, T. S. (2007). Contriving motivating operations to evoke mands for information in preschoolers with autism. Research in Autism Spectrum Disorders, 3, 210-217.

Esbenshade, P. H., \& Rosales-Ruiz, J. (2001). Programming common stimuli to promote generalized question-asking. Journal of Positive Behavior Interventions, 3, $199-210$

Fahey, G. (1942). The question activity of children. Journal of Genetic Psychology, 60, 337-357.

Ganz, J. B., Davis, J. L., Lund, E. M., Goodwyn, F. D., \& Simpson, R. L. (2012). Meta-analysis of PECS with individuals with ASD: Investigation of targeted versus nontargeted outcomes, participant characteristics, and implementation phase. Research in Developmental Disabilities, 33, 406-418.

Ganz, J. B., Earles-Vollrath, T. L., Heath, A. K., Parker, R. I., Rispoli, M., \& Duran, J. B. (2012). A meta-analysis of single case research studies on aided augmentative and alternative communication systems with individuals with autism spectrum disorders. Journal of Autism and Developmental Disorders, $42,60-74$.

Gast, D. (2010). Single subject research methodology in behavioral sciences. New York: Routledge.

Hartman, E. C., \& Klatt, K. P. (2005). The effects of deprivation, presession exposure, and preferences on teaching manding to children with autism. The Analysis of Verbal Behavior, 21, 135-144.

Hung, D. W. (1977). Generalization of 'curiosity' questioning behavior in autistic children. Journal of Behavior Therapy and Experimental Psychiatry, 8, 237-245.

Ingvarsson, E. T., \& Hollobaugh, T. (2010). Acquisition of intraverbal behavior: Teaching children with autism to mand for answers to questions. Journal of Applied Behavior Analysis, 43, 1-17.

Koegel, L. K., Camarata, S. M., Valdez-Menchaca, M. C., \& Koegel, R. L. (1998). Setting generalization of question-asking by children with autism. American Journal on Mental Retardation, 102, 346-357.

Koegel, L. K., Carter, C. M., \& Koegel, R. L. (2003). Teaching children with autism self-initiations as a pivotal response. Topics in Language Disorders, 23, 134-145.

Koegel, L. K., Koegel, R. L., Green-Hopkins, I., \& Barnes, C. C. (2010). Brief report: Question-asking and collateral language acquisition in children with autism. Journal of Autism and Developmental Disorders, 40, 509-515.

Langthorne, P., \& McGill, P. (2009). A tutorial on the concept of the motivating operation and its importance to application. Behavior Analysis in Practice, 2, 22-31.

Lechago, S. A., Carr, J. E., \& Grow, L. L. (2010). Mands for information generalize across establishing operations. Journal of Applied Behavior Analysis, 43, 381-395.

Lewis, M. M. (1938). The beginning and early functions of questions in a child's speech. British Journal of Educational Psychology, 8, 150-171.

Light, J. C., \& Binger, C. (1998). Building communicative competence with individuals who use augmentative and alternative communication. Baltimore: Paul H Brookes Publishing Co.

Marion, C., Martin, G. L., \& Yu, C. T. (2011). Teaching children with autism spectrum disorder to mand what is it? Research in Autism Spectrum Disorders, 5, 15841597.

Ostryn, C., \& Wolfe, P. S. (2011a). Teaching children with autism to ask what's that? Using a picture communication with vocal results. Infants $\mathcal{E}^{\prime}$ Young Children, 24 $174-192$.

Ostryn, C., \& Wolfe, P. S. (2011b). Teaching preschool children with autism spectrum disorders to expressively discriminate between "what's that?" and "where is it?". Focus on Autism and Other Developmental Disabilities, 26, 195-205.

Palmen, A., Didden, R., \& Arts, M. (2008). Improving question asking in high-functioning adolescents with autism spectrum disorders: Effectiveness of small-group training. The Autism, 12, 83-98.

Panico, J., Daniels, D. E., \& Claflin, M. (2011). Working in the classroom with young children who stutter. Young Children, 66, 91-95.

Ramdoss, S., Mulloy, A., Lang, R., O’Reilly, M., Sigafoos, J., Lancioni, G., et al. (2011). Use of computer-based interventions to improve literacy skills in students with autism spectrum disorders: A systematic review. Research in Autism Spectrum Disorders, 5, 1306-1318.

Roy-Wsiaki, G., Marion, C., Martin, G. L., \& Yu, C. T. (2010). Teaching a child with autism to request information by asking 'what?'. Developmental Disabilities Bulletin, 38, 55-77.

Secan, K. E., Egel, A. L., \& Tilley, C. S. (1989). Acquisition, generalization, and maintenance of question answering skills in autistic children. Journal of Applied Behavior Analysis, 22, 181-196.

Shillingsburg, M. A., \& Valentino, A. L. (2011). Teaching a child with autism to mand for information using how. Analysis of Verbal Behavior, $27,179-184$.

Shillingsburg, M. A., Valentino, A. L., \& Bowen, C. N. (2011). Teaching children with autism to request information. Research in Autism Spectrum Disorders, 5, 670679.

Skinner, B. F. (1957). Verbal behavior. Englewood Cliffs, NJ: Prentice Hall.

Skinner, B. F. (1982). Contrived reinforcement. The Behavior Analyst, 5, 3-8.

Smith, M. (1933). The influence of age, sex, and situation on the frequency, form, and function of questions asked by preschool children. Child Development, 4, 201381 .

Stokes, T. F., \& Baer, D. M. (1977). An implicit technology of generalization. Journal of Applied Behavior Analysis, 11, 285-303.

Stone, W. L., Ousley, O. Y., Yoder, P. J., Hogan, K. L., \& Hepburn, S. L. (1997). Non-verbal communication in two- and three-year-old children with autism. Journal of Autism and Developmental Disorders, 27, 677-696.

Sundberg M. L. Loeb, M., Hale, L. \& Eigenheer, P. (2002). Contriving establishing operations to teach mands for information. Analysis of Verbal Behavior, 18, 15-29.

Sundberg, M. L., \& Michael, J. (2001). The benefits of Skinner's analysis of verbal behavior for children with autism. Behavior Modification, $25,698-724$.

Sundberg, M. L., \& Partington, J. W. (1998). Teaching language to children with autism or other developmental disabilities. Pleasant Hill, CA: Behavior Analysts Inc.

Taylor, B. A., \& Harris, S. L. (1995). Teaching children with autism to seek information: Acquisition and generalization of responding. Journal of Applied Behavior Analysis, 28, 3-14.

Tyack, D., \& Ingram, D. (1977). Children's production and comprehension of questions. Journal of Child Language, 4, $211-224$.

van der Meer, L., \& Rispoli, M. (2010). Communication intervention involving speech-generating devices for children with autism: A review of the literature. Developmental Neurorehabilitation, 13, 294-306.

Wetherby, A. M., \& Prutting, C. A. (1984). Profiles of communicative and cognitive social abilities in autistic children. Journal of Speech and Hearing Research, 27, 364-377.

Williams, G., Donley, C. R., \& Keller, J. W. (2000). Teaching children with autism to ask questions about hidden objects. Journal of Applied Behavior Analysis, 33, 627630.

Williams, G., Perez-Gonzalez, L. A., \& Vogt, K. (2003). The role of specific consequences in the maintenance of three types of questions. Journal of Applied Behavior Analysis, 36, 285-296. 